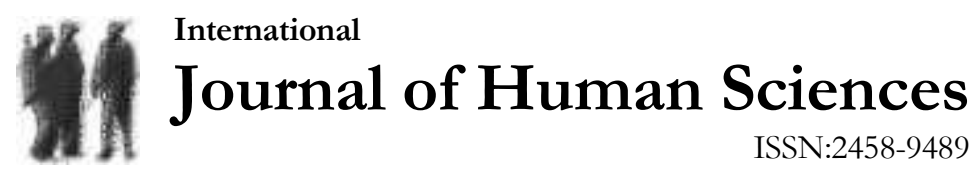

Volume 16 Issue 4 Year: 2019

\section{Seeding and gold medal probability in wrestling: a 2016 Rio Olympic Games analysis ${ }^{1}$}

\author{
İlkay Doğan ${ }^{2}$ \\ Özkan Işık ${ }^{3}$ \\ Mehmet Cüneyt Birkök ${ }^{4}$
}

\begin{abstract}
The United World Wrestling carried out the implementation of seeding athletes for the first time at the 2016 Rio Olympic Games. For this reason, the aim of the current study was to calculate the probability of winning a medal and becoming an Olympic Champion at the 2016 Rio Olympic Games of seeded wrestlers using the Bayesian theorem. The data were obtained from the results book of the Rio Olympic Games. The obtained data were analyzed Bayesian theorem. According to the results, the probabilities of being an Olympic Champion of first seeded wrestlers were $67.0 \%$, $81.0 \%$ and $62.0 \%$ for males Greco-Roman, freestyle and female freestyle, respectively. As a result, being a seeded athlete had a great advantage to become an Olympic Champion in the wrestling competitions of the Rio Olympic Games. As the Olympic Games are held every four years, the medals in the Grand Prix tournaments, continental, and World Championships must be scored according to difficulty grade and medal colour, and the Olympic ranking should be established for each weight category. Furthermore, it would provide more competitive, challenging and enjoyable Olympic Games for wrestling and spectators.
\end{abstract}

Keywords: Bayesian theorem; Competition; Performance; Seeded athletes; Wrestlers

\footnotetext{
${ }^{1}$ Abstract of this study was presented as an oral presentation at 6th International Conference on Science Culture and Sport, 25-27 Apr 2018, Lviv-Ukraine.

2 Assist. Prof., Gaziantep University, Faculty of Medicine, Department of Biostatistics, ilkay dgn58@hotmail.com (iD) Orcid ID: 0000-0001-7552-6478

3 Assoc. Prof., Balıkesir University, School of Physical Education and Sports, Coaching Education, ozkanisik86@hotmail.com (iD) Orcid ID: 0000-0003-2561-1695

${ }^{4}$ Assoc. Prof., Sakarya University, Faculty of Education, birkok@sakarya.edu.tr (DD Orcid ID: 0000-0001-7915-1116 


\section{Introduction}

Many countries have been investing millions of dollars in order to participate in the Olympics with more athletes and to achieve a better result (Guilheiro \& Franchini, 2017; Rees et al., 2016). In wrestling, one of the oldest sports in Olympic history (Isik \& Gumus, 2018), participating in the Olympic Games are very important for wrestlers. Olympic Wrestling is performed in three different styles: males freestyle and Greco-Roman, and females freestyle. Each style of the wrestling has eight different weight categories in tournaments, continental championships, and world championships. However, in the Olympic Games, wrestling has six different weight categories (https://www.olympic.org/rio-2016/wrestling). In all Olympic Games until the Rio Olympics Games, the athletes were ranked as a result of the drawings by the United World Wrestling (UWW). The matches were determined according to this drawing. However, in this application, the best two athletes in the same weight category could face each other on the qualification tours and one of the best athletes could be eliminated. Therefore, the implementation of being seeded criteria was used for the first time in Rio Olympics by the UWW. According to this application, in the 2015 Wrestling World Championships, the athletes who were the finalists in the Olympic weight categories took place in different pools as being seeded. Gold medal wrestlers in Olympic weight categories at the 2015 World Championships were automatically placed in the number one drawing and the silver medal wrestlers were automatically placed in the number nine drawing as seeded athletes at the Rio Olympic Games. Other athletes were ranked in their weight categories by drawing. Furthermore, if athletes who were finalists in the Olympic weight category in the final World Championship before the Olympic Games could not participate in the Olympic Games, the other athlete in the same weight category from that country would be ranked at the end of the draw. Moreover, only one athlete would be seeded for this weight category and also other athletes of different countries for this weight category would be ranked at the end of the draw. (https://unitedworldwrestling.org/governance/regulations-olympic-wrestling).

Athletes, coaches, and national wrestling federations do not have any certain knowledge about the possible impact of being a seeded athlete on success, since being a seeded athlete is a new criterion. For this reason, this research can be valuable for athletes, coaches, and national wrestling federations. Moreover, it may be the reason for choosing the athletes whom the federations wanted to compete in the Olympic Games.

A total of 19 to 21 athletes competed in each weight category at the Rio Olympic Games in 2016 (https://www.olympic.org/rio-2016/wrestling). The number one and number nine seeded athletes in each weight category made a maximum of three matches until they were finalists. However, the other athletes ranked by drawing had a possibility of doing four matches. Thus, the seeded athletes could be a finalist with less total effort in the Olympic Games. The aim of the present study was to calculate the probability of winning medals at the Rio Olympic Games in 2016 as compared to other wrestlers and the possibility of becoming an Olympic Champion using the Bayesian theorem.

\section{Method and material}

\subsection{Data Set}

The data used in this research were obtained from the Rio Olympic Games results' book. Data from athletes who took part in the Rio 2016 Olympic Games were included in the current study. Totally 235 male (116 athletes for Greco-Roman and 119 athletes for freestyle) and 112 female wrestlers from six weight categories for each style. In these competitions, 34 athletes were seeded (two for each weight category in each style) and 72 medals were distributed. Two athletes (men's freestyle $97 \mathrm{~kg}$ and women's freestyle $75 \mathrm{~kg}$ ) could not participate in the Rio Olympic Games despite being seeded athlete (https://www.olympic.org/rio-2016/wrestling). For this reason, these two athletes were not included in the study as seeding. 


\subsection{Bayes Theorem}

If the probability $\mathrm{P}(\mathrm{A})$ of an event $\mathrm{A}$ is affected by another $\mathrm{B}$ event, it is called conditional probability $\mathrm{P}(\mathrm{A} \mid \mathrm{B})$. $\mathrm{P}(\mathrm{A} \mid \mathrm{B})$ indicates the probability of event $\mathrm{A}$ when the probability of event $\mathrm{B}$ is known. Bayes theorem is derived from the definition of conditional probability. The Bayes formula for a single event is:

$$
P(A \mid B)=\frac{P(B \mid A) P(A)}{P(B)}=\frac{P(B \mid A) P(A)}{P(B \mid A) P(A)+P\left(B \mid A^{c}\right) P\left(A^{c}\right)}
$$

Bayes theorem can be generalized for $\mathrm{N}$ events (Guner, 2014).

$$
\mathrm{P}\left(A_{i} \mid \mathrm{B}\right)=\frac{\mathrm{P}\left(\mathrm{B} \mid A_{i}\right) \mathrm{P}\left(A_{i}\right)}{\mathrm{P}(\mathrm{B})}=\frac{\mathrm{P}\left(\mathrm{B} \mid A_{i}\right) \mathrm{P}\left(A_{i}\right)}{\sum_{i=1}^{N} \mathrm{P}\left(\mathrm{B} \mid A_{i}\right) \mathrm{P}\left(A_{i}\right)}
$$

As a first step in the current study, the probability of winning the Olympic medals $(\mathrm{P}(\mathrm{M} \mid \mathrm{C})$ ) was calculated for seeded athletes using the Bayes theorem, in a similar way as conducted with judo athletes competing in London and Rio Olympics (Guilheiro and Franchini, 2017). Explanations of the variables used in this calculation and a sample calculation are given below.

a) $\mathrm{P}(\mathrm{M})$ : the initial probability of an athlete, seeded or non-seeded, winning a medal is equal to $\mathrm{M} / \mathrm{N}$ where $\mathrm{M}=$ number of medals at stake; $\mathrm{N}=$ number of competitors;

b) $\mathrm{P}\left(M^{c}\right)$ : the probability of an athlete, seeded or non-seeded, not winning a medal is equal to 1$\mathrm{P}(\mathrm{M})$

c) $\mathrm{P}(\mathrm{S} \mid \mathrm{M})$ : the probability of being a seeded athlete given this athlete won a medal is equal to $\mathrm{W} / \mathrm{M}$, where $\mathrm{W}=$ number of seeded athletes who won a medal;

d) $\mathrm{P}\left(\mathrm{S} \mid M^{c}\right)$ : the probability of being a seeded athlete given this athlete did not win a medal is equal to $\mathrm{L} /(\mathrm{N}-\mathrm{M})$, where $\mathrm{L}=$ number of seeded athletes who did not win a medal.

Thus, the probability of getting an Olympic medal given the athlete was seeded (finalist of pre- Olympic World Championship) compared to non-seeded was calculated by:

$$
P(\mathrm{M} \mid \mathrm{C})=\frac{P(\mathrm{M}) * P(C \mid \mathrm{M})}{P(M) * P(C \mid \mathrm{M})+P\left(M^{c}\right) * P\left(C \mid M^{c}\right)}
$$

According to Table 1, for example, the probability of an athlete getting an Olympic medal in Rio 2016; given that this athlete was seeded in the under 59-kg weight category is equal to:

$$
\frac{0.21 * 0.25}{0.21 * 0.25+0.79 * 0.07} \cong 0.50
$$

As a second step in the current study, the probabilities of being the Olympic Champion of the first seeded athletes $(\mathrm{P}(\mathrm{O} \mid \mathrm{FS}))$ were calculated using the Bayes theorem. Explanations of the variables used in this calculation and a sample calculation are given below.

a) $\mathrm{P}(\mathrm{O})$ : the initial probability of the first seeded athlete being an Olympic Champion is equal to $\mathrm{OC} / \mathrm{SA}$, where $\mathrm{OC}=$ number of Olympic Champions; $\mathrm{SA}=$ number of Seeded Athletes;

b) $\mathrm{P}\left(O^{c}\right)$ : the probability of the first seeded athlete not being an Olympic Champion is equal to $1-\mathrm{P}(\mathrm{O})$

c) $\mathrm{P}(\mathrm{FS} \mid \mathrm{O})$ : the probability of being the first seeded athlete given this athlete was Olympic Champion is equal to FS/FS+SS, where FS=number of first seeded athletes who were Olympic Champions; $\mathrm{SS}=$ number of seeded athletes who were Olympic Champions; 

analysis. Journal of Human Sciences, 16(4), 931-937. doi:10.14687/jhs.v16i4.5819

d) $\mathrm{P}\left(\mathrm{FS} \mid O^{c}\right)$ : the probability of being the first seeded athlete given this athlete was not the Olympic Champion is equal to FS not Gold Medal/ (FS not Gold Medal+ SS not Gold Medal)

Thus, the probability of being an Olympic Champion of the first seeded athletes compared to other athletes was calculated by:

$$
P(\mathrm{O} \mid \mathrm{FS})=\frac{P(0) * P(F S \mid 0)}{P(0) * P(F S \mid 0)+P\left(O^{c}\right) * P\left(F S \mid O^{c}\right)}
$$

According to Table 2, for example, the probability of an athlete being an Olympic Champion given that this athlete was the first men's Greco-Roman seeded in his category is equal to:

$$
\frac{0.50 * 0.75}{0.50 * 0.75+0.50 * 0.38} \cong 0.67
$$

\subsection{Ethical Approval}

Olympic Games results of Olympic weight categories for all styles of wrestling were retrieved from the Olympic Games results book. Official permission for using data was obtained from the Olympic Studies Centre of the International Olympic Committee for this study.

\section{Results}

Table 1. Basic variables and probabilities of getting an Olympic medal for the seeded athletes com-

\begin{tabular}{|c|c|c|c|c|c|c|c|c|c|}
\hline Gender \& Weight \& Still & $\mathrm{M}$ & $\mathrm{N}$ & W & $\mathrm{L}$ & $\mathrm{P}(\mathrm{M})$ & $\mathrm{P}\left(M^{c}\right)$ & $\mathrm{P}(\mathrm{S} \mid \mathrm{M})$ & $\mathrm{P}\left(\mathrm{S} \mid M^{c}\right)$ & $\mathbf{P}(\mathrm{S} \mid \mathrm{C})$ \\
\hline \multicolumn{10}{|l|}{ Men’s Greco-Roman } \\
\hline 59 & 4 & 19 & 1 & 1 & 0.21 & 0.79 & 0.25 & 0.07 & 0.50 \\
\hline 66 & 4 & 18 & 0 & 2 & 0.22 & 0.78 & 0.00 & 0.14 & 0.00 \\
\hline 75 & 4 & 20 & 2 & 0 & 0.20 & 0.80 & 0.50 & 0.00 & 1.00 \\
\hline 85 & 4 & 21 & 1 & 1 & 0.19 & 0.81 & 0.25 & 0.06 & 0.50 \\
\hline 98 & 4 & 19 & 2 & 0 & 0.21 & 0.79 & 0.50 & 0.00 & 1.00 \\
\hline 130 & 4 & 19 & 2 & 0 & 0.21 & 0.79 & 0.50 & 0.00 & 1.00 \\
\hline \multicolumn{10}{|l|}{ Men's Freestyle } \\
\hline 57 & 4 & 20 & 2 & 0 & 0.20 & 0.80 & 0.50 & 0.00 & 1.00 \\
\hline 65 & 4 & 21 & 2 & 0 & 0.19 & 0.81 & 0.50 & 0.00 & 1.00 \\
\hline 74 & 4 & 20 & 1 & 1 & 0.20 & 0.80 & 0.25 & 0.06 & 0.50 \\
\hline 86 & 4 & 19 & 2 & 0 & 0.21 & 0.79 & 0.50 & 0.00 & 1.00 \\
\hline 97 & 4 & 19 & 1 & 0 & 0.21 & 0.79 & 0.25 & 0.00 & 1.00 \\
\hline 125 & 4 & 20 & 1 & 1 & 0.20 & 0.80 & 0.25 & 0.06 & 0.50 \\
\hline \multicolumn{10}{|l|}{ Women's Freestyle } \\
\hline 48 & 4 & 18 & 2 & 0 & 0.22 & 0.78 & 0.50 & 0.00 & 1.00 \\
\hline 53 & 4 & 19 & 2 & 0 & 0.21 & 0.79 & 0.50 & 0.00 & 1.00 \\
\hline 58 & 4 & 20 & 1 & 1 & 0.20 & 0.80 & 0.25 & 0.06 & 0.50 \\
\hline 63 & 4 & 19 & 1 & 1 & 0.21 & 0.79 & 0.25 & 0.07 & 0.50 \\
\hline 69 & 4 & 18 & 1 & 1 & 0.22 & 0.78 & 0.25 & 0.07 & 0.50 \\
\hline 75 & 4 & 18 & 0 & 1 & 0.22 & 0.78 & 0.00 & 0.07 & 0.00 \\
\hline
\end{tabular}
pared to non-seeded for Rio Olympic Games 2016

Note. M: number of medals; N: number of competitors; W: number of seeded athletes who won a medal; L: number of seeded athletes who did not win a medal

The possibility of winning a medal of seeded athletes varied from 0 in the Greco-Roman male 66 $\mathrm{kg}$ and freestyle female $75 \mathrm{~kg}$ categories to $100 \%$ in the Greco-Roman male $75 \mathrm{~kg}$, $98 \mathrm{~kg}$, and 130 $\mathrm{kg}$, freestyle male $57 \mathrm{~kg}$. $65 \mathrm{~kg}, 86 \mathrm{~kg}, 96 \mathrm{~kg}$, and freestyle female $48 \mathrm{~kg}$ and $53 \mathrm{~kg}$ categories. For all other categories, the probability was $50 \%$. 

analysis. Journal of Human Sciences, 16(4), 931-937. doi:10.14687/jhs.v16i4.5819

Table 2. Basic variables and probabilities of being an Olympic Champion of the first seeded athletes compared to other athletes for Rio Olympic Games 2016

\begin{tabular}{lccc}
\hline Variables & Men's Greco-Roman & Men's Freestyle & Women's Freestyle \\
\hline OC & 6 & 6 & 6 \\
SA & 12 & 11 & 11 \\
FS Gold Medal & 3 & 4 & 2 \\
SS Gold Medal & 1 & 0 & 1 \\
FS did not win Gold Medal & 3 & 2 & 4 \\
SS did not win Gold Medal & 5 & 5 & 4 \\
$\mathrm{P}(\mathrm{O})$ & 0.50 & 0.55 & 0.55 \\
$\mathrm{P}\left(\boldsymbol{O}^{c}\right)$ & 0.50 & 0.45 & 0.45 \\
$\mathrm{P}(\mathrm{FS} \mid \mathrm{O})$ & 0.75 & 1.00 & 0.67 \\
$\mathrm{P}\left(\mathrm{FS} \mid \boldsymbol{O}^{c}\right)$ & 0.38 & 0.29 & 0.50 \\
$\mathbf{P}(\mathbf{O} \mid$ FS $)$ & $\mathbf{0 . 6 7}$ & $\mathbf{0 . 8 1}$ & $\mathbf{0 . 6 2}$
\end{tabular}

Note. The variables OC, SA, FS, SS, FS that did not win Gold Medal, and SS that did not win Gold Medal were used to calculate the probabilities used in Bayes Formula. OC: number of Olympic Champions; SA: number of seeded athletes; FS: number of first seed athletes who won the gold medal; SS: number of second seed athletes who won the gold medal

It was determined that the probability of being the Olympic Champion of first seeded athletes were $67.0 \%, 81.0 \%$, and $62.0 \%$ for male Greco-Roman and freestyle and female freestyle, respectively.

\section{Discussion}

The main findings of the present study were that there was a huge variation concerning the probability of seeded athletes winning an Olympic medal in the different wrestling styles and weight categories (i.e., from 0 to $100 \%$ ), but that in general the probability of the first seeded athlete to become Olympic champion was quite high (from 62\% to $81 \%$ ) when the different styles were considered as whole.

In a sportive context, one form of inducing preferential treatment can be observed in contests where competitors are seeded based on past performance. In national and/or international competitions of many sports (e.g. tennis, football, and judo) the seeded application is implemented (Arabzad, Ghorbani \& Shirouyehzad, 2014; Hizan, Whipp \& Reid, 2011; Julio et al., 2015). In any sport, seeding favours the reputable competitors by affording them a theoretically easier route to the championship (Waguespack \& Salomon, 2015). However, in combat sports, the ranking position seems to be a poor predictor of the final result during the Olympic Games (Franchini \& Julio, 2015) and World Championships in judo (Vellosa Breviglieri et al., 2018), and some weight categories (Krumer, 2017) are more balanced than others.

In past competitions, wrestlers were aligned by drawing lots for each weight category. At the end of this lineup, the world's famous wrestlers could compete against each other in the initial phases of the competition, and one of them was eliminated. This resulted in the attractiveness of the semi-final and final matches becoming decreased for spectators. For this reason, the UWW used the criteria of being seeded for the first time in 2016 Rio Olympics Games. According to this rule, the finalists of the Olympic weight categories in the last pre-Olympic World Championship were automatically ranked. Thus, the wrestlers who were seeded in the Olympic Games could be the finalists with fewer matches than the other wrestlers, and the two best wrestlers in the same weight category did not meet each other until the final match, or in the repechage or bronze medal match (if both or one of them were defeated before the final match, respectively). This system provided an advantage for the seeded athletes to become a champion in the Olympics. According to this criterion, it became very important for athletes to be a finalist in the final pre-Olympic World Championship. 

analysis. Journal of Human Sciences, 16(4), 931-937. doi:10.14687/jhs.v16i4.5819

\section{Conclusions and recommendations}

Our results indicated that the seeded wrestlers in the Rio Olympic Games had a high advantage of being an Olympic Champion. Conversely, the probability of winning a medal for male and female judo athletes (Guilheiro and Franchini, 2017) were lower than the probability of winning a medal for male and female wrestlers. Specifically, Guilheiro and Franchini (2017) have reported that the probability of seeded athletes to win a medal was $41.1 \%$ and $42.9 \%$ for male judo athletes and 35.7\% and 44.6\% for female judo athletes at London 2012 and Rio 2016, respectively. Therefore, considering this difference, wrestlers will likely give more importance to the World Wrestling Championship organized 11 months before the Olympic Games to increase their chance to be Olympic champion or get an Olympic medal. This has made the final pre-Olympic World Championship increase its relevance for these athletes. Additionally, Olympic ranking rules should be introduced for wrestling. This rule should cover all the periods between two Olympic Games; all Grand Prix tournaments, Continental and World Championships must be rated according to difficulty ratings, medal colours, and the Olympic ranking should be established for each weight category, as used in other combat sports. The real Olympic performances of the athletes may emerge with this rule. Furthermore, athletes can participate in more tournaments for their Olympic weight categories, and thus the quality of tournaments will increase. Another relevant suggestion is to increase to four or eight the number of seeded athletes for each Olympic weight category. In this way, higher quality matches could be watched in the quarter or semi-finals in the Olympic Games.

In summary, a great variation concerning the probability of seeded athletes winning an Olympic medal in the different wrestling styles and weight categories (i.e., from 0 to 100\%) were observed in the present study. However, the probability of the first seeded athlete to become the Olympic champion was quite high (from $62 \%$ to $81 \%$ ) when the different styles were considered as whole.

\section{Acknowledgments}

The study was financially funded by Afyon Kocatepe University, Scientific Research Coordination Department with protocol number 18.KARIYER.121. Finally, authors thanks to Emerson Franchini for his scientific contribution and editing.

\section{References}

Arabzad, S. M., Ghorbani, M., \& Shirouyehzad, H. (2014). A new hybrid method for seed determination in sport competitions: the case of European Football Championship 2012. International Journal of Industrial and Systems Engineering, 17(3), 259-274.

Franchini, E., \& Julio, U. F. (2015). The judo world ranking list and the performances in the 2012 London Olympics. Asian journal of sports medicine, 6(3), e24045.

Guilheiro, L. M., \& Franchini, E. (2017). Be seeded or not be seeded? A study with Olympic judo athletes. Journal of exercise rebabilitation, 13(2), 148-152.

Guner, A. (2014). Bayesci Yaklaşımda Eşlenik Aileleri Önseli ile Jeffreys Önselinin Karşılaştırılması. [Comparison of Conjugate Families' Prior and Jeffreys' Prior in Bayesian Aproach. In Turkish] (Unpublished Master's thesis, Eskişehir Osmangazi University). Department of Statistics, Institute of Science and Technology.

Hizan, H., Whipp, P., \& Reid, M. (2011). Comparison of serve and serve return statistics of high performance male and female tennis players from different age-groups. International Journal of Performance Analysis in Sport, 11(2), 365-375.

International Wrestling Rules Book, Version January, 2018. (2018). Retrieved Feb 25, 2018 from: https://unitedworldwrestling.org/governance/regulations-olympic-wrestling.

Isik, O., \& Gumus, H. (2018). Evaluation of effective demographic variables in competition performances of Turkish wrestling referees. Journal of Human Sport and Exercise, 13(1): 60-71. 
Julio, U. F., Miarka, B., Rosa, J. P., Lima, G. H., Takito, M. Y., \& Franchini, E. (2015). Blue judogi may bias competitive performance when seeding system is not used: sex, age, and level of competition effects. Perceptual and motor skills, 120(1), 28-37.

Krumer, A. (2017). On winning probabilities, weight categories, and home advantage in professional judo. Journal of Sports Economics, 18(1), 77-96.

Rees, T., Hardy, L., Güllich, A., Abernethy, B., Côté, J., Woodman, T., ... \& Warr, C. (2016). The great British medalists project: a review of current knowledge on the development of the world's best sporting talent. Sports Medicine, 46(8), 1041-1058.

Results book of Rio Olympic Games. (2016). Retrieved Feb 20, 2018 from: https://www.olympic.org/rio-2016/wrestling.

Waguespack, D. M., \& Salomon, R. (2015). Quality, subjectivity, and sustained superior performance at the Olympic Games. Management Science, 62(1), 286-300.

Velloso Breviglieri, P., Soares Possa, M. E., Moura Campos, V., Humberstone, C., \& Franchini, E. (2018). Judo world ranking lists and performance during cadet, junior and senior World Championships. Ido Movement for Culture. Journal of Martial Arts Anthropology, 18(2), 48-53. 